\title{
Community Health Workers Increase the Rate of HIV Disclosure Among HIV Affected Heterosexual Partners in Rural Uganda; A Cluster Non- Randomized Controlled Trial
}

\section{Zubair Lukyamuzi ( $\nabla$ zlukyamuzi@mujhu.org )}

Makerere University, Johns Hopkins University Collaboration (MU-JHU)

\section{Bashir Ssuna}

Uganda Tuberculosis Implementation Research Consortium (U-TIRC)

Ruth Nabisere Mirembe

Infectious Diseases Institute (IDI), College of Health Sciences, Makerere University, Kampala, Uganda

\section{Rita Nakalega}

Makerere University, Johns Hopkins University Collaboration (MU-JHU)

\section{Patience Atuhaire}

Makerere University, Johns Hopkins University Collaboration (MU-JHU)

\section{Philippa Musoke}

Makerere University, Johns Hopkins University Collaboration (MU-JHU)

\section{Lisa M Butler}

University of Connecticut- Institute for Collaboration on Health, Intervention, and Policy

\section{Research Article}

Keywords: HIV status disclosure, Community Health Worker, Sexual relationships, facilitators of disclosure, time to disclosure

Posted Date: February 1st, 2022

DOI: https://doi.org/10.21203/rs.3.rs-1241246/v1

License: (c) (i) This work is licensed under a Creative Commons Attribution 4.0 International License. Read Full License 
Title: Community health workers increase the rate of HIV disclosure among HIV affected heterosexual partners in rural Uganda; a cluster non-randomized controlled trial

Authors: Zubair Lukyamuzi ${ }^{1,2}$, Bashir Ssuna $^{3}$, Ruth Nabisere Mirembe ${ }^{4}$, Rita Nakalega ${ }^{1}$, Patience Atuhaire ${ }^{1}$, Philippa Musoke ${ }^{1}$, Lisa M Butler ${ }^{5}$

\section{Affiliations}

${ }^{1}$ Makerere University, Johns Hopkins University Collaboration (MU-JHU), Upper Mulago Hill Road, Kampala, Uganda

${ }^{2}$ Makerere University College of Health Sciences, School of Public Health

${ }^{3}$ Uganda Tuberculosis Implementation Research Consortium (U-TIRC)

${ }^{4}$ Infectious Diseases Institute (IDI), College of Health Sciences, Makerere University, Kampala, Uganda

${ }^{5}$ University of Connecticut USA- Institute for Collaboration on Health, Intervention, and Policy

\section{Corresponding author}

\section{Zubair Lukyamuzi}




\section{Abstract}

Background: HIV disclosure is a critical component of HIV prevention and treatment programs. Community Health Workers (CHW) play an important role in HIV disclosure counseling among HIV-affected heterosexual partners. However, time to disclosure attributed to the use of $\mathrm{CHW}$ in the disclosure process remains undocumented. This study assessed the effect of $\mathrm{CHW}$-facilitated counseling on time to partner disclosure among Adults living with HIV (ALHIV) in the greater Luwero region, Uganda

Methods: We conducted a two-arm cluster, non-randomized controlled trial. HIV care facilities in the greater Luwero region were allocated to either the intervention or control arm. Eligible participants were ALHIV in heterosexual partnerships who had never disclosed to their current partners. In the control arm, participants received routine regular facility-based counseling. In the intervention arm, alongside usual care, participants received $\mathrm{CHW}$-facilitated disclosure counseling. Data were collected at baseline, 3 and 6 months with the primary outcome of disclosure. Survival analysis with proportional hazard ratios was used to determine the time to disclosure in both arms.

Results: A total of 245 participants were enrolled, of whom complete data were available for 230 (93.9\%). Of these, $112(48.7 \%)$ were in the intervention arm and $118(51.3 \%)$ were in the control arm. Mean \pm SD age was $31 \pm 8$ years with a range of 18 to 55 years. More participants were females 176 (76.5\%). The cumulative incidence of disclosure was higher in the intervention arm 8.76 [95\% Cl: 7.20-10.67] per 1,000 person-time versus 5.15 [95\%Cl: 4.85-6.48] per 1,000 person-time in the control arm, log-rank test, $\mathrm{X}^{2}=12.93, \mathrm{P}<0.001$.

Male gender, $\mathrm{aHR}=1.82$ [95\% Cl: 1.26-2.65], tertiary education, aHR = 1.51 [95\% Cl: $1.43-1.60]$ and relationship duration of $>6$ months, aHR $=1.19$ [95\% Cl: 1.16-1.22] predicted disclosure. Prior disclosure to a relative, aHR = 0.55 [95\% Cl: $0.39-0.78]$ and having $>1$ sexual partner in the past 3 months, aHR $=0.74$ [95\% Cl: 0.60-0.92] predicted non-disclosure

Conclusion: CHW-led counseling increased the rate of partner HIV disclosure among ALHIV in heterosexual partnerships. Therefore, $\mathrm{CHW}$-facilitated counseling may be used to quicken disclosure, reduce stigma and improve HIV treatment outcomes among ALHIV with disclosure difficulties. 
Keywords: HIV status disclosure, Community Health Worker, Sexual relationships, facilitators of disclosure, time to disclosure 


\section{Introduction}

Human Immunodeficiency Virus (HIV) remains a major public health problem worldwide with 38 million people globally infected by 2020 (1). Despite a 23\% decline in new HIV infections since 2010, overall, 690,000 AIDSrelated deaths and 1.7 million new infections occurred in 2019 leading to a failure to achieve the 2020 targets of reducing AIDS-related deaths to fewer than 500000 and new HIV infections to fewer than 500000 (1,2). Despite contributing only $12 \%$ of the world's population, Sub-Saharan Africa (SSA) remains an epicenter for HIV with $71 \%$ of the world's people living with HIV(PLWH) (3). Eastern and Southern Africa remain the most affected regions despite registering 38\% largest reduction in new HIV infections in 2019 (1)

HIV infection affects all groups of people but those in sexual partnerships are the most affected (3-5). In Uganda, approximately $10 \%$ of sexual couples are affected by HIV (3). In the management of HIV, HIV status disclosure is fundamentally important (6-8) but HIV non-disclosure remains a complex and critical challenge (9) affecting both concordant and discordant couples $(10,11)$. Approximately $30 \%$ of PLWH have not disclosed to their partners in Uganda (12-14). HIV status non-disclosure is associated with poor ART adherence, development of resistant strains, and increased HIV transmission (15-17). Apart from the prevention and care benefits of HIV disclosure $(18,19)$, disclosure promotes social support and a sense of wellbeing by enhancing trust and social acceptance (20-22). Disclosure is a process and might not be a one-time event (23) and it is always hindered by anticipation of negative reactions including stigma and couple separation; however, a non-significant number of such occur upon disclosure (23-25). Disclosure can be done by the PLWH themselves or significant others such as health workers on behalf of the client after their consent (26).

Various factors are reported to influence disclosure $(27,28)$ and these can be categorized into barriers and facilitators of disclosure in a specific type of relationship $(26,29,30)$. Disclosure varies greatly among sexual partners, but it is generally lower with casual partners than regular partners. Financial dependence, literacy, many sexual partners, index testing during Antenatal care, not being on ART, lack of communication skill, younger age, female gender, and fear of negative consequences of disclosure negatively affects disclosure $(13,14,19,21)$. However, receipt of ongoing disclosure counseling, longer duration of follow up in HIV care, being a member of HIV/AIDS association, having the responsibility to disclose, need for social support, peer support, and knowing partner's HIV status increases disclosure $(13,14,18,26)$. However, disclosure is also influenced by social 
desirability bias with $15.4 \%$ and $6.7 \%$ of men and women respectively claiming to have disclosed and yet didn't (31).

The duration taken to disclose also varies widely from the time of HIV diagnosis to many years of living with the disease mediated by socio-demographics (18). A shorter duration to HIV disclosure leads to the quicker achievement of HIV management outcomes and reducing HIV transmission; hence contributing to the realization of global targets of ending HIV by $2030(32,33)$. Professional facilitated couple counseling and assisted partner notification (APN) may quicken disclosure; however, there is a scarcity of trained health cadres in low-resource settings and the approaches are more of facility-based than community-based (34-37). In addition to their several roles in HIV care (38-41), Community Health workers have shown to improve disclosure among ALHIV in a heterosexual relationship (42). However, the time to disclosure attributed to CHW remained not clear. Therefore, in this study we compared time to disclosure in a $\mathrm{CHW}$ led intervention group to the routine regular counseling among ALHIV in heterosexual partners in the greater Luwero region. 
Methods: The methods of this study were primarily used to compare the proportion of partner disclosure among ALHIV supported by CHW to those who received routine regular counseling (42).

Study design: This was a Cluster non-randomized longitudinal study conducted from $03^{\text {rd }}$ October 2019 to $31^{\text {st }}$ May 2020 in the greater Luwero region. We compared HIV disclosure among sub-counties (clusters) allocated intervention (CHW intervention) with sub-counties (clusters) allocated to control (without $\mathrm{CHW}$ intervention). Because the intervention required interaction between study participants and their respective $\mathrm{CHWs}$ within the community or village, blinding of study participants and randomization were not appropriate for this study. Therefore, to minimize the possibility of intervention dilution, intervention and control clusters were separated by a longitudinal geographical barrier (buffer zone). All potential participants from the buffer zone were excluded from the study as shown in fig 1.

Fig. 1 recruitment of participants from their respective clusters

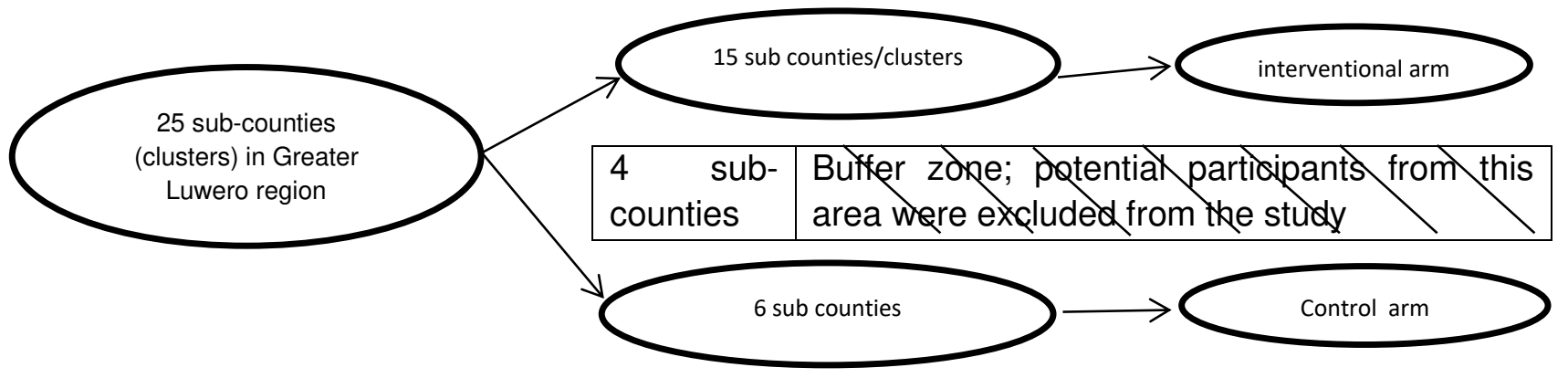

Study area and population: The study area was the greater Luwero region located about $20 \mathrm{~km}$ from Kampala and it is comprised of 3 sub-districts which were Luwero, Nakaseke, and Nakasongola district. The region constituted 25 sub-counties which served as clusters in this study. In Uganda, a sub-county consisted of approximately 6 parishes and is headed by an elected local council III (LCIII) chairman; and each parish consisted of several villages or zones. Therefore, 15 sub-counties (clusters) were allocated intervention, 6 allocated control and 4 formed the buffer zone. Sub counties for the control arm were bigger than those in the intervention arm. Greater Luwero region had a population of about 949,100 served by 3 government Hospitals, 1 private not-forprofit Hospital, and 7 Health Center IVs (HCIV). In Uganda, an HCIV was managed by a doctor, offers surgical services and other general health services including HIV care $(43,44)$. The study sites were the high volume (busiest) HIV care clinics in the above-mentioned facilities except for one government military hospital which provided us with administrative approval towards the end of the project period; hence being unable to conduct the study in that facility. Therefore, we recruited participants from 10 health facilities which were; 3 hospitals: 
Luwero, Nakaseke, Kiwoko hospital; and 7 HCIV: Semuto, Nyimbwa, Kalagala, Ngoma, Nakasongola, Nabiswera, and St. Francis HCIV.

The study participants were Adults living with HIV (ALHIV) who had been in sexual relationships for at least 3 months and had not disclosed their HIV-positive status to their current heterosexual partner(s).

Community health workers intervention: CHWs (lay health workers) were members of the communities where they come from and had training in providing various basic health care services including HIV care. After recruitment, each participant from the clusters allocated intervention was asked to provide the name and contact (if they were known to the participant) of a $\mathrm{CHW}$ in their locality or village. A given CHW's name was verified in the district $\mathrm{CHW}$ registry. A verified $\mathrm{CHW}$ was contacted, informed about the study, and scheduled for training if they were interested. A total of $48 \mathrm{CHWs}$ were contacted and trained for 3 days. The covered topics included; refresher HIV basic counseling skills, HIV status disclosure skills, health ethics, confidentiality and privacy, and management of adverse events associated with disclosure such as domestic violence and separation. The training was done using both role play and didactic models moderated by HIV counselors and study investigators. Pre- and post-training assessments were done.

Each trained $\mathrm{CHW}$ was linked to their respective participant(s). Therefore, 121 (who had been recruited in the intervention arm) participants were attached to $48 \mathrm{CHWs}$ in the ratio of 3:1. Upon getting in touch, the $\mathrm{CHW}$ and participant would initially meet and lay a specific disclosure plan. Generally, the plan included: 2 weekly phone calls and scheduled home visits. Discussions during these phone calls and home visits would involve disclosure methods and strategies; assessing partner(s) attitude, personality, and availability; and potential adverse outcomes. Depending on the outcomes and agreements from the discussions during the disclosure plan, eventual disclosure would occur at home or the health facility depending on the participant's preference.

Disclosure at the home would involve; a participant disclosing themselves to the partner in the presence or absence of a CHW, or a CHW would disclose to the participant's partner on the participant's behalf in their presence.

Disclosure at the health facility would involve a CHW encouraging and arranging for the couple HIV testing and counseling at a health facility of the participant's choice. At the facility, disclosure would be done by the facility health worker taking the participant to be as if they were newly diagnosed with no prior awareness of their HIV positivity. 
CHWs received ongoing supervision via regular phone calls and meetings with the study team. CHWs would also complete a home visit and phone call log whenever they visited or telephoned the participant for study purposes.

Control (usual care): Participants continued to receive routine regular (standard of care) at their respective HIV care centers. This care involved continuous disclosure counseling. With this counseling, participants would to partners themselves at home or persuade their partners to go for couple HIV counseling and testing at the health facility. At the health facility, a health worker would consider the participant be as if they were newly diagnosed with no prior awareness of their HIV positivity.

Outcomes: The primary outcome was time to disclosure during a follow-up period of 6 months. This was obtained from $\mathrm{CHW}$ and /or participants reporting successful disclosure (events) at 3 monthly subsequent in-clinic study visits. For participants who disclosed that their partners were not aware of their HIV status, participants were encouraged to bring them for HIV counseling and testing. Otherwise, all who disclosed were encouraged to bring their partners to the study site or health facility for further counseling and possible HIV testing.

Independent variables were; $\mathrm{CHW}$ intervention, age, education, gender, marital status, nature of marriage, duration of the relationship, monthly income, partner HIV status, duration on ART, condom use, person priory disclosed to, membership to an HIV/AIDs association, place of HIV diagnosis, prior receipt of disclosure counseling, negative attitude towards other people knowing one's HIV status, feeling a responsibility to disclose, ever had chance(s) to disclose (such as partner asking for couple HIV testing)

\section{Sample size and sampling procedures}

We estimated the sample size using a formula for two proportions;

$$
N=\frac{\left[z_{z} \sqrt{P(1-P)\left(1 / q_{1}+1 / q_{2}\right)}+z_{\beta} \sqrt{P_{1}\left(1-P_{1}\right)\left(1 / q_{1}\right)+P_{2}\left(1-P_{2}\right)\left(1 / q_{2}\right)}\right]^{2}}{\left(P_{1}-P_{2}\right)^{2}} .
$$

Where P1 was the proportion of participants expected to have the outcome (disclosing HIV status) in the control group. P2 was the proportion of participants expected to have the outcome (disclosing HIV-positive status) in the intervention group. q1 was the proportion of participants expected not to have an outcome (not disclosing HIV positive status) in the control group, q2 was the proportion of participants expected not to have an outcome (not disclosing HIV positive status) in the intervention group, $\mathrm{P}=\mathrm{q} 1 \mathrm{P} 1+\mathrm{q} 2 \mathrm{P} 2$ and $\mathrm{N}$ is the total number of participants. Assuming that participants in the control group were not to disclose their status after the study follow-up, $\mathrm{P} 1=0 \%$. Using a previous study that had looked at the role of community health workers in improving Tuberculosis sputum positive case detection on the 
scale(45), we assumed that CHWs would increase the proportion of the outcome (disclosure) by $7 \%$, hence $\mathrm{p} 2=0.07$. Taking equal numbers in the two groups, $\mathrm{q} 1=\mathrm{q} 2=0.5$, we got an $\mathrm{N}$ of 214 . Accounting for loss to follow up at $10 \%$, the adjusted $\mathrm{N}$ was 236 , having 118 participants in each group.

Data collection procedures: For both arms, participants were recruited between 3rd October 2019 and 7th November 2019. ALHIV who came in for HIV services at the study sites were informed about the study and those who met the eligibility criteria were consented and recruited. The eligibility criteria were; an adult (above 18years), HIV positive in a heterosexual relationship for at least 3 months, had not disclosed their HIV status to their current sexual partner(s), stayed in the study area (greater Luwero region) for at least 3 months and willing to provide informed consent. Those who were coming from the study buffer zone were excluded from the study. In total, about 8 participants were recruited per day across all study sites.

Participants completed a questionnaire at enrollment and then reviewed and assessed for disclosure at 3 months and 6 months.

Using district $\mathrm{CHW}$ registry, $\mathrm{CHW}$ from clusters that were allocated intervention were conveniently contacted, trained, consented, and recruited in the study. Following recruitment, $\mathrm{CHW}$ were linked to the participants who were coming from their locality.

The study endpoints were HIV disclosure or study end period (6 months) whichever came first. Those who experienced adverse events upon disclosure continued to receive study team counseling and psycho-social support until they reconciled or end of 6 months whichever came first.

Statistical analysis: Data were collected using REDcap_v8.5.11 then transferred into an excel sheet and later transferred to STATA 15/MP for analysis (46). Univariately, data were summarized using descriptive texts and summarizing tables and graphs. Continuous variables like age were summarized as mean with standard deviation (SD) while categorical variables were summarized as frequencies, proportions in Tables and graphs.

The overall time of survival (failure to disclose) was determined. Kaplan Meier survival curve was used to estimate the disclosure rate. Disclosure rate was calculated as the number of participants who disclosed divided by the total number of participants recruited expressed as number per 1,000 person-years. Survival curves were presented. Cox regression analysis was used to assess for the factors influencing disclosure or non-disclosure at the end of follow-up and presented as Hazard ratios (HR) with their $95 \%$ confidence intervals at both bivariate and multivariate levels. All variables with a $\mathrm{P}<0.2$ as well as those variables known to influence disclosure were 
entered in multivariate cox regression. A p-value of 0.05 was considered statistically significant. Confounding was assessed and all variables that cause a $\geq 10 \%$ change in crude and adjusted models were considered a confounder

Results: Screening and enrollment procedures were done at the study sites and participants were recruited, randomized and data were analyzed as shown in the fig. 2

Fig.2 below shows the number of participants evaluated at each stage of the study.

\section{Approach}

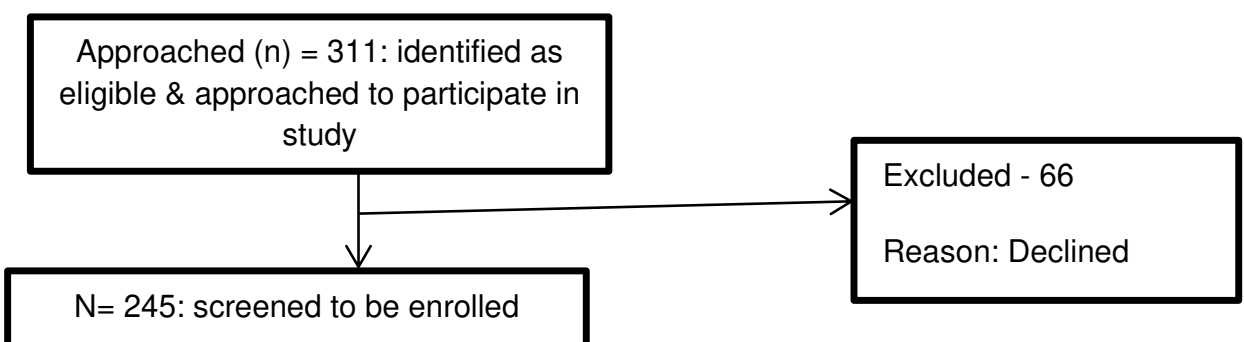

\section{Enrollment and allocation}

Control arm

\section{Cluster allocation /enrollment}

\section{Intervention arm

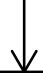

Allocated to control cluster/ arm, $n=124$

Received control arm procedures, $n=124$

Discontinued control procedures, $\mathrm{n}=0$
Allocated to intervention cluster/ arm, $n=121$

Received intervention procedures, $n=121$

Discontinued the intervention, $\mathrm{n}=0$

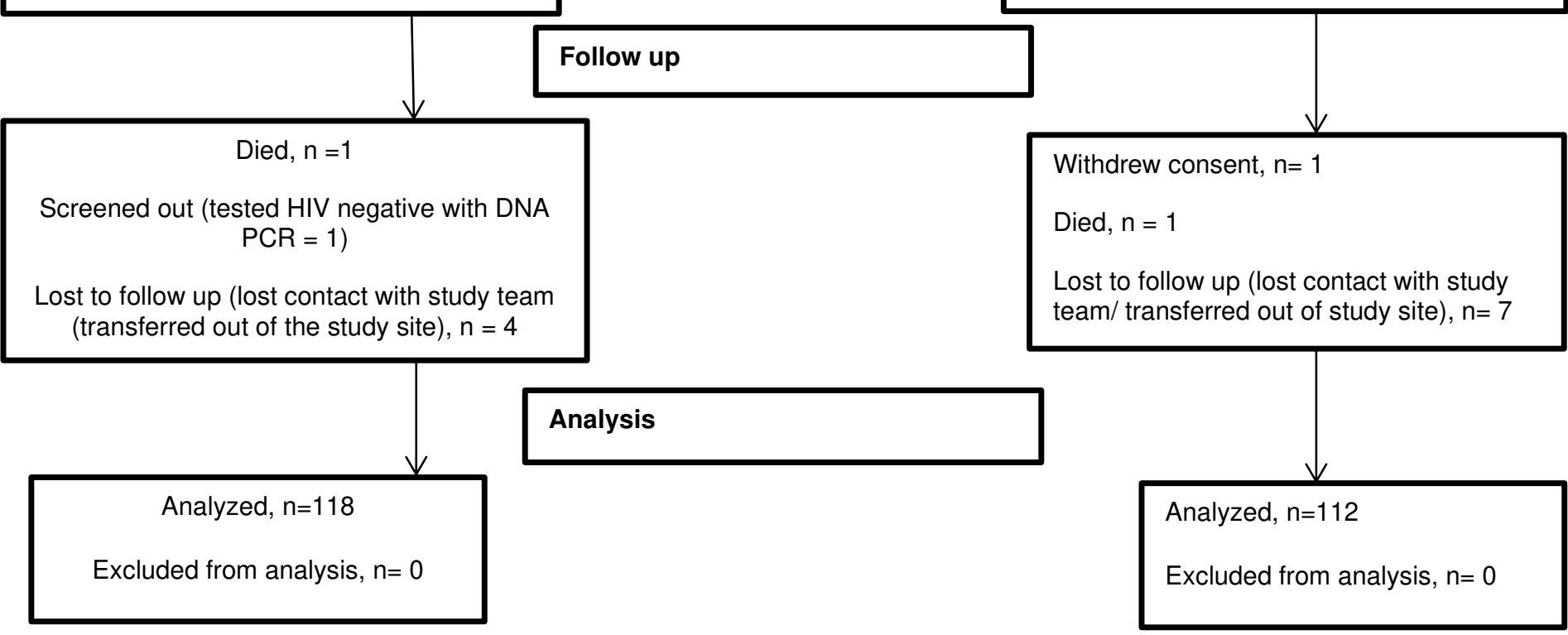

\section{Description of study participants}

A total of 245 participants were recruited from 10 health facilities with an average of 25 participants per facility. Two facilities recruited participants in both study arms and the rest recruited in either CHW intervention or control arm. A total of 230 (93.9\%) participants completed the study and of these, $112(48.7 \%)$ were in the CHW 
intervention and $118(51.3 \%)$ were in the control arm. The median age was $30(I Q R=25-37)$ years. The majority of those recruited in the $\mathrm{CHW}$ intervention arm were females 95 (84.8\%) as shown in table 1.

Table 1: Demographic characteristics of participants in the intervention compared to control arm

\begin{tabular}{|c|c|c|c|c|}
\hline Characteristic & $\begin{array}{l}\text { Sample size (\%) } \\
\mathrm{N}=245\end{array}$ & $\begin{array}{l}\text { Intervention } \mathrm{n}(\%) \\
\mathrm{N}=112\end{array}$ & $\begin{array}{l}\text { Control n (\%) } \\
\mathrm{N}=118\end{array}$ & P-value \\
\hline Age group (years) & & & & 0.102 \\
\hline $18-35$ & $163(70.9)$ & $85(75.9)$ & $78(66.1)$ & \\
\hline $35-55$ & $67(29.1)$ & $27(24.1)$ & $40(33.9)$ & \\
\hline Gender & & & & 0.004 \\
\hline Female & $176(76.5)$ & $95(84.8)$ & $81(68.6)$ & \\
\hline Male & $54(23.5)$ & $17(15.2)$ & $37(31.4)$ & \\
\hline Education & & & & 0.019 \\
\hline None & $30(13.0)$ & $12(10.7)$ & $18(15.3))$ & \\
\hline Primary & $122(53.1)$ & $52(46.4)$ & $70(59.3)$ & \\
\hline Secondary & $67(29.1)$ & $39(34.8)$ & $28(23.7)$ & \\
\hline Tertiary & $11(4.8)$ & $9(8.0)$ & $2(1.7)$ & \\
\hline Marital status & & & & 0.008 \\
\hline Casual partner & $60(26.1)$ & $22(19.6)$ & $38(32.2)$ & \\
\hline Cohabiting & $139(60.4)$ & $68(60.7)$ & $71(60.2)$ & \\
\hline Married & $21(9.1)$ & $22(19.6)$ & $9(7.6)$ & \\
\hline Nature of Marriage & & & & 0.019 \\
\hline Monogamous & $13(5.7)$ & $8(7.1)$ & $5(4.2)$ & \\
\hline Polygamous & $18(7.8)$ & $14(12.5)$ & $4(3.4)$ & \\
\hline Not mentioned & $199((86.5)$ & $90(80.4)$ & $109(92.4)$ & \\
\hline Duration of relationship & & & & 0.521 \\
\hline$<6$ months & $14(6.1)$ & $5(4.5)$ & $9(7.6)$ & \\
\hline 6 months -1 year & $57(24.8)$ & $30(26.8)$ & $27(22.9)$ & \\
\hline$>1$ year & $159(69.1)$ & $77(68.8)$ & $82(69.5)$ & \\
\hline Monthly income & & & & 0.989 \\
\hline$<120,000$ & $147(63.9)$ & $72(64.3)$ & $75(63.6)$ & \\
\hline $120,000-500,000$ & $77(33.5)$ & $37(33.0)$ & $40(33.9)$ & \\
\hline$>500,000$ & $6(2.6)$ & $3(2.7)$ & $3(2.5)$ & \\
\hline
\end{tabular}

\section{Behavioral and HIV associated characteristics}

The majority $184(80 \%)$ of the participants didn't know their sexual partners' HIV status. Among sexual partners whose HIV status was known by participants, 38/40 (82.6\%) were negative. All participants were on ART and 194 (79.81\%) had disclosed to either a friend or relative, and $51(20.82 \%)$ had never disclosed to anyone. Only 13 (5.7\%) participants were members of the HIV group or association (such as being peer educators). The majority, $182(79.1 \%)$ participants had ever received partner disclosure counseling by a health worker at their respective HIV care centers. The majority of the participants $120(52.2 \%)$ reported having a negative attitude towards other people knowing their HIV status as shown in table 2. 
Table 2: Clinical characteristics of participants in the intervention compared to control arm

\begin{tabular}{|c|c|c|c|c|}
\hline Characteristic & $\begin{array}{l}\text { Sample size } \\
(\%) N=245\end{array}$ & $\begin{array}{l}\text { Intervention } \mathrm{n}(\%) \\
\mathrm{N}=112\end{array}$ & $\begin{array}{l}\text { Control n (\%) } \\
\mathrm{N}=118\end{array}$ & P-value \\
\hline Partner HIV status & & & & 0.049 \\
\hline Negative & $38(16.5)$ & $12(10.7)$ & $26(22.0)$ & \\
\hline Positive & $8(3.5)$ & $3(2.7)$ & $5(4.2)$ & \\
\hline Don't know & $184(80.0)$ & $97(86.6)$ & $87(73.7)$ & \\
\hline Duration on ART & & & & 0.001 \\
\hline$<6$ months & $55(23.9)$ & $38(33.9)$ & $17(14.4)$ & \\
\hline 6 months- 1 year & $31(13.5)$ & $10(8.9)$ & $21(17.8)$ & \\
\hline$>1$ year & $144(62.6)$ & $64(57.1)$ & $80(67.8)$ & \\
\hline Condom use & & & & 0.191 \\
\hline No & 130(56.5) & $68(60.7)$ & $62(52.5)$ & \\
\hline Sometimes & $83(36.1)$ & $39(34.8)$ & $44(37.3)$ & \\
\hline Always & $17(7.4)$ & $5(4.5)$ & $12(10.2)$ & \\
\hline Person priory disclosed to & & & & 0.050 \\
\hline No & $39(17.0)$ & $24(21.4)$ & $15(12.3)$ & \\
\hline Friend & $21(9.1)$ & $6(5.4)$ & $15(12.7)$ & \\
\hline Relative & $170(73.9)$ & $82(73.2)$ & $88(74.6)$ & \\
\hline Place where tested HIV from & & & & 0.033 \\
\hline ANC Clinic & $59(25.7)$ & $32(28.6)$ & $27(22.9)$ & \\
\hline VCT Clinic & 149(64.8) & $75(67.0)$ & $74(62.7)$ & \\
\hline Other & $22(9.6)$ & $5(4.5)$ & $17(14.4)$ & \\
\hline $\begin{array}{l}\text { Membership } \\
\text { association }\end{array}$ to $\quad$ HIV/AIDS & & & & 0.127 \\
\hline No & 217(94.3) & 103(92.0) & 114(96.6) & \\
\hline Yes & $13(5.7)$ & $9(8.0)$ & $4(3.4)$ & \\
\hline $\begin{array}{l}\text { Prior receipt of disclosure } \\
\text { counseling }\end{array}$ & & & & 0.004 \\
\hline No & $48(20.9)$ & $27(24.1)$ & $21(17.8)$ & \\
\hline Always & $37(16.1)$ & $8(7.1)$ & $29(24.6)$ & \\
\hline Only at testing & $75(32.6)$ & $42(37.5)$ & $33(28.0)$ & \\
\hline Sometimes & $70(30.4)$ & $35(31.3)$ & $35(29.7)$ & \\
\hline $\begin{array}{l}\text { Negative attitude towards other } \\
\text { people knowing one's HIV status }\end{array}$ & & & & 0.005 \\
\hline No & $110(47.8)$ & $43(38.4)$ & $67(56.8)$ & \\
\hline Yes & $120(52.2)$ & $69(61.6)$ & $51(43.2)$ & \\
\hline Feeling a responsibility to disclose & & & & 0.140 \\
\hline No & 22(9.6) & $14(12.5)$ & $8(6.8)$ & \\
\hline Yes & 208(90.4) & $98(87.5)$ & $110(93.2)$ & \\
\hline \multicolumn{5}{|l|}{$\begin{array}{l}\text { Having a conducive disclosure } \\
\text { environment }\end{array}$} \\
\hline No & 166(72.2) & $93(83.0)$ & $73(61.9)$ & $<0.001$ \\
\hline Yes & $64(27.8)$ & 19(17.0) & $45(38.0)$ & \\
\hline
\end{tabular}


Two hundred thirty (230) participants were followed up for a total period of 25290 person-time. 118 (51.3\%) participants were in the control arm with a total follow-up period of 13,992 person-time while $112(48.7 \%)$ were in the intervention arm with a follow-up for a period of 11,298 person-time. In the control arm, 72/118 (61\%) participants disclosed their HIV status within the follow-up period at a disclosure rate of 5.15 [95\% $\mathrm{Cl}: 4.85-6.48]$ per 1,000 person-time while 99/112 (88.4\%) participants disclosed in the intervention arm within the follow-up period at a rate of 8.76 [95\% Cl: $7.20-10.67]$ per 1,000 person-time as shown in fig. 3 .

\section{Fig.3: disclosure to sexual partners among ALHIV by study arm}

Disclosure by study arm

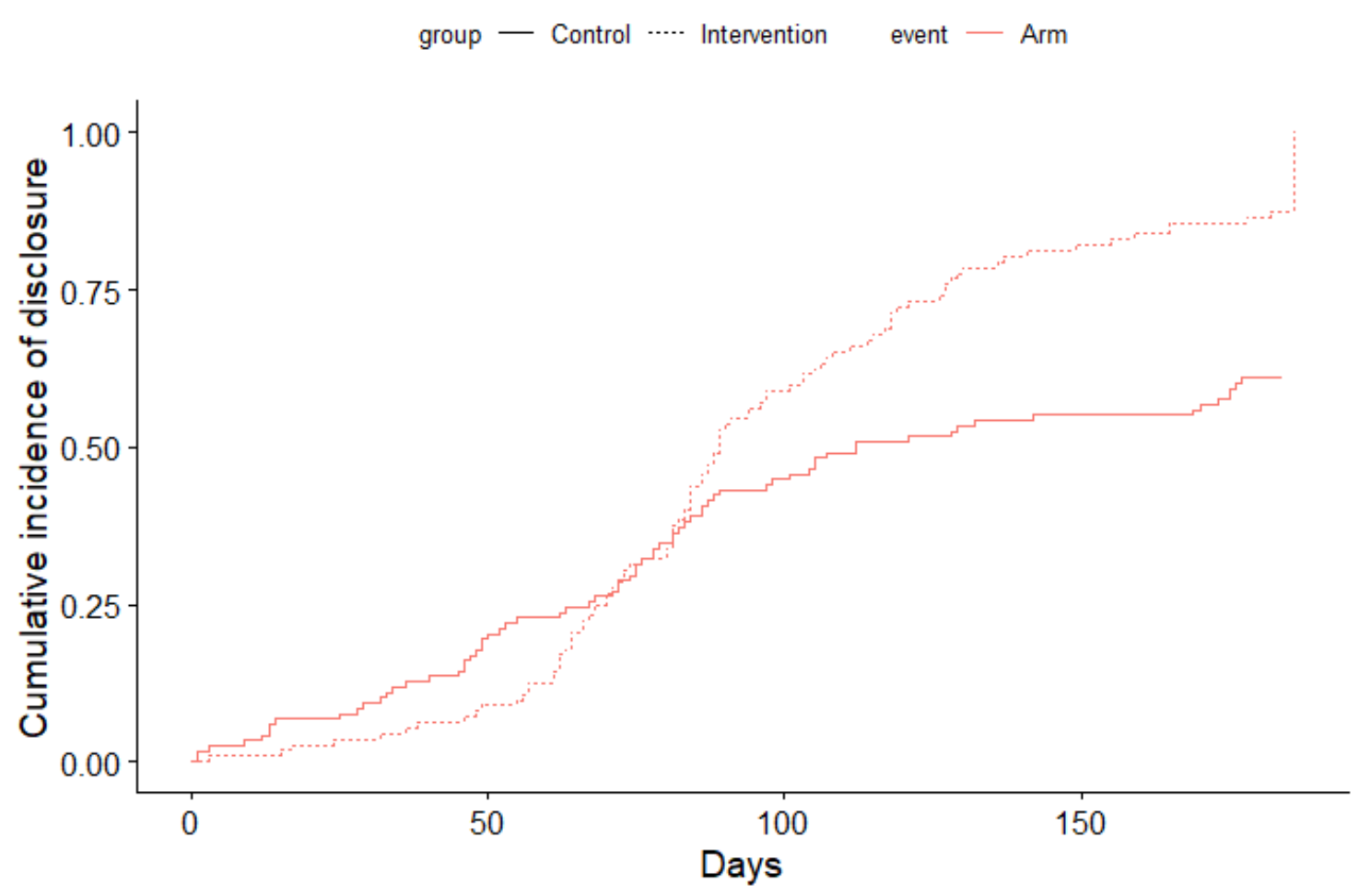

In the first 50 days of follow-up, the probability of disclosure was slightly higher in the control arm than in the intervention arm. However, the probability of disclosure exponentially increased in the subsequent 70 days for the intervention arm nearly doubling that in the control arm. The probability of disclosure between the control and intervention arms was statistically significant by log-rank test, $X^{2}=12.93, P<0.001$ as shown in figure 4. 
Fig. 4: Cumulative incidence disclosure to sexual partners among ALHIV

Cumulative incidence functions

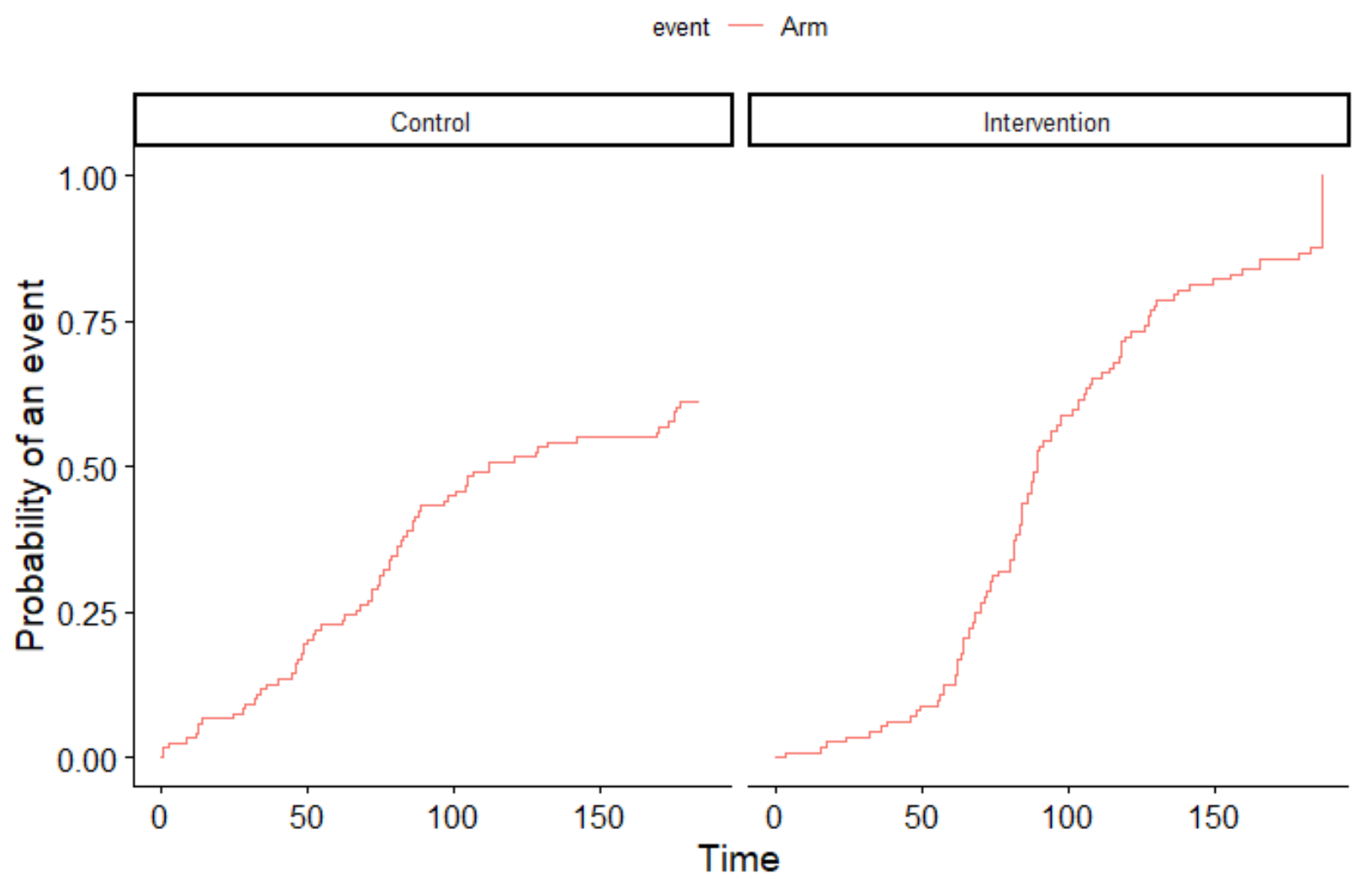

Predictors of HIV status disclosure to sexual partners among ALHIV

Male gender, aHR $=1.82[95 \% \mathrm{Cl}: 1.26-2.65]$, tertiary education, $\mathrm{aHR}=1.51[95 \% \mathrm{Cl}: 1.43-1.60]$ and relationship duration of $>6$ months, aHR $=1.19$ [95\% Cl: $1.16-1.22]$ predicted disclosure. Prior disclosure to a relative, aHR $=$ 0.55 [95\% Cl: $0.39-0.78]$ and having $>1$ sexual partners in the past 3 months, aHR $=0.74$ [95\% Cl: $0.60-0.92]$ predicted non-disclosure as shown in table 3 
Table 3: predictors of disclosure to sexual partners among ALHIV

\begin{tabular}{|c|c|c|c|}
\hline Characteristic & Crude HR (95\% Cl) & Adjusted HR (95\% Cl) & P-value \\
\hline \multicolumn{4}{|l|}{ Gender } \\
\hline Female & 1.00 & 1.00 & \\
\hline Male & $1.57[1.12-2.20]$ & $1.82[1.26-2.65]$ & 0.002 \\
\hline \multicolumn{4}{|l|}{ Education } \\
\hline None & 1.00 & 1.00 & \\
\hline Primary & $1.08[0.66-1.76]$ & $1.22[0.42-3.53]$ & 0.709 \\
\hline Secondary & $1.18[0.71-1.98]$ & $1.29[0.51-3.27]$ & 0.590 \\
\hline Tertiary & $1.86[0.87-3.97]$ & $1.51[1.43-1.60]$ & $<0.001$ \\
\hline \multicolumn{4}{|c|}{ Duration of relationship } \\
\hline$<6$ months & 1.00 & 1.00 & \\
\hline 6 months -1 year & $0.61[0.47-0.80]$ & $1.19[1.16-1.22]$ & $<0.001$ \\
\hline$>1$ year & $0.61[0.57-0.66]$ & $1.32[1.32-1.33]$ & $<0.001$ \\
\hline \multicolumn{4}{|c|}{ Person disclosed to } \\
\hline None & 1.00 & 1.00 & \\
\hline Friend & $0.35[0.34-0.36]$ & $0.35[0.04-2.95]$ & 0.336 \\
\hline Relative & $0.56[0.40-0.78]$ & $0.55[0.39-0.78]$ & 0.001 \\
\hline \multicolumn{4}{|c|}{ Place where tested HIV from } \\
\hline ANC Clinic & 1.00 & 1.00 & \\
\hline VCT Clinic & $1.12[1.01-1.24]$ & $1.36[1.34-1.39]$ & $<0.001$ \\
\hline Other & 1.24 [0.66-2.33] & $1.76[0.62-5.00]$ & 0.290 \\
\hline \multicolumn{4}{|c|}{ Received disclosure counseling } \\
\hline No & 1.00 & 1.00 & \\
\hline Always & $0.54[0.45-0.66]$ & $0.84[0.57-1.25]$ & 0.400 \\
\hline Only at testing & $1.33[1.10-1.62]$ & $2.13[0.69-6.62]$ & 0.191 \\
\hline Sometimes & $0.50[0.45-0.56]$ & $0.61[0.38-0.98]$ & 0.040 \\
\hline \multicolumn{4}{|c|}{$\begin{array}{l}\text { Need a community health worker to } \\
\text { help }\end{array}$} \\
\hline No & 1.00 & 1.00 & \\
\hline Yes & $1.44[0.93-2.22]$ & $1.66[0.90-3.05]$ & 0.105 \\
\hline \multicolumn{4}{|c|}{ Sexual partners in the last 3 months } \\
\hline None & 1.00 & 1.00 & \\
\hline One & $0.26[0.05-1.32]$ & $0.68[0.39-1.21]$ & 0.189 \\
\hline More than one & $0.39[0.10-1.49]$ & $0.74[0.60-0.92]$ & 0.006 \\
\hline \multicolumn{4}{|c|}{ Circumcision status } \\
\hline No & 1.00 & 1.00 & \\
\hline Yes & $1.51[1.22-1.85]$ & $1.32[1.13-1.13-1.53]$ & $<0.001$ \\
\hline
\end{tabular}




\section{Discussion}

$\mathrm{CHW}$ intervention increased the rate of disclosure to 8.76 per 1,000-person-time from 5.15 per 1,000 person-time in the control group. Male gender, $\mathrm{aHR}=1.82$, tertiary education, $\mathrm{aHR}=1.51$ and relationship duration of $>6$ months, aHR $=1.19$ predicted disclosure. Whereas prior disclosure to a relative, aHR $=0.55$, and having $>1$ sexual partner in the past 3 months, aHR $=0.74$ predicted non-disclosure. The implications of these findings are as follows;

The findings suggest that $\mathrm{CHW}$ quickened disclosure in rural Ugandan settings. To our knowledge, this is the first study to determine the rate of disclosure among ALHIV using CHW-led intervention counseling. This means for the two groups followed for the same period, a greater number of ALHIV supported by CHW could disclose their HIV-positive status to sexual partners compared to those who are not supported by the CHW. Despite being a non-comparative and having a different study population, Exavery et al' reported similar community-based findings of accelerated disclosure among Orphans and Vulnerable Children to caregivers to community-based lay social welfare volunteers (47). Relatedly various studies have shown the role of $\mathrm{CHW}$ in improving HIV care services (48-52). However, all these studies were none comparative and never considered time to the intended outcome. In contrast, some studies have not shown a significant difference in achieving HIV management outcomes using $\mathrm{CHW}$ interventions (53-55). Our findings may suggest that as the world is striving to hasten the nearing global targets of ending HIV/AIDs by 2030 (32), faster HIV stigma reduction interventions such as the current intervention may be critically important. The current evidence also suggests that $\mathrm{CHWs}$ can reduce the workload of health workers in counseling and monitoring PLHIV with disclosure difficulties.

In this study, the male gender predicted disclosure, a similar finding reported in other studies $(18,56-58)$. Men were more likely to disclose in this study probably due to financial independence and reduced fear of financial support implications following disclosure which has been commonly found in women $(26,29,30)$. However, many studies have also reported that women are more likely to disclose than men (59-61) and others have not found gender-specific significant differences in sexual partner disclosure (62). These differences may probably be due to different study settings, interventions, and study populations 
Relationship duration of more than 6 months predicted disclosure, this a similar finding to Mbichila et al study's cross-sectional study in which he found that PLHIV in sexual relationships for more than 1 year had 0.82 more odds of disclosure to sexual partners compared to those who had been in a relationship for less than 1 year (63). Another study in Tanzania also reported that the proportion of disclosure increased with the duration of the relationship (64). This finding may imply that as the relationship grows older, there is increasing understanding of each, trustworthy, and bonding. Additionally, newer or non-marital partnerships may feel more vulnerable to accusations of infidelity or being infected before beginning their current partnership $(64,65)$, hence preventing them from disclosure.

Tertiary education predicted disclosure, a similar finding from Shacham et al study in which they reported that higher levels of education were associated with disclosure (66). This is because individuals with higher levels of education may feel comfortable and confident to disclose their status to sexual partners and may also be financially stable which is reported to be associated with disclosure (64). Greater education is also reported to be a protective effect of disclosure as reported by Tesfaye et al (67). It is said that PLHIV with higher educational levels may better understand the benefits of HIV disclosure to sexual partners or have an easier time discussing personal and intimate aspects with a partner that involves their HIV serological status (68). Other studies have reported a similar effect of tertiary education on HIV-positive status disclosure (69, 70). However, a study done in Tanzania did not find any association between education status and HIV disclosure to a sexual partner (64). This is likely to be due to different study populations whereby the Tanzanian study was done among pregnant women as opposed to that was conducted in ALHIV.

Prior disclosure to a relative also predicted disclosure. It is reported that disclosure to a relative usually happens first and this relative may help the PLHIV cope with the news of their HIV diagnosis and then may encourage and prepare them to disclose to significant others especially sexual partners (71). However, Abdool et al found a discrepant finding for which disclosure to sexual partners was overall approximately $65 \%$ less likely if a person had initially disclosed to their family (72). Antelman et al also reported that prior disclosure to a female relative was not associated with sexual partner disclosure (64). These differences may be due to differences in the study population and study variables.

Having more than one sexual partner, predicted non-disclosure a similar finding was reported in Tanzania where HIV-positive individuals with more than six life sexual partners were less likely to disclose (64). Other studies have reported similar findings $(19,21)$. Having many sexual partners is socially judged as infidelity and 
promiscuous. Therefore, to avoid such judgments and accusations, disclosure may be deferred among those with more than one sexual partner.

\section{Study strengths and limitations}

To the best of our knowledge, this is one of the first studies to empirically and specifically assess the relative incidence of partner disclosure in a $\mathrm{CHW}$ led intervention. The creation of a buffer zone minimized intervention dilution and contamination between study arms that may be associated non blinded interventional studies. Finally, the study did not only depend on self-reported disclosure but also checked with CHW and the non-study partner (upon obtaining consent from the participant) to confirm that HIV disclosure happened. This reduced social desirability bias.

The results of this study are limited by the non-randomized nature of the study clusters which may be prone to selection bias or confounding. Some study sites recruited participants in both study arms hence a possibility of intervention dilution; however, such sites first recruited participants in the intervention arm and then in the control arm. Moreover, participants of different study arms had different scheduled study visits hence minimizing the possibility of these participants meeting at the facility (study site). There was a variation in participants' characteristics between study arms. This was probably due non-randomized nature of the study clusters and participants or disproportionate among PLHIV receiving HIV care (e.g., there more women in HIV care than men). However, the variables which were strong predictors of disclosure were adjusted for in the analysis.

\section{Conclusion}

$\mathrm{CHW}$ led counseling intervention is associated with a higher incidence of disclosure compared to routine regular counseling in rural Uganda. These findings imply that in the essence hastening the achievement of the nearing global targets of ending HIV by 2030 , CHW led disclosure strategy may be utilized to quicken stigma reduction and improve adherence to treatment and care among those ALHIV with partner disclosure difficulties.

\section{Declarations;}

\section{Availability of data and materials}

The datasets used and/or analyzed during the current study are not available to the public to protect it from unintended disclosure or possible theft. However, it is available from the corresponding author on reasonable request. 


\section{Ethics approval and consent to participate}

The protocol was reviewed and approved by the school of medicine Institutional Review Board (IRB) - Makerere University (REC REF 2019-100). Additional clearance was sought from the National Council of science and technology (HS443ES). The district health departments granted permission to undertake the study. Informed written consent was obtained from all participants; confidentiality and anonymity were strictly observed at all the research stages. Participant safety was ensured throughout the study and all study procedures were performed in accordance with relevant guidelines and regulations.

\section{Author Contributions}

ZL: conceptualized the study, RNM and ZL: participated in data collection and its management and drafted the manuscript. BS: conducted the analysis. PM\& LMB: supported and guided conceptualization, data collection and management, and manuscript drafting. RN \&PA: contributed to the conceptualization of the study and data management. All authors reviewed the manuscript and provided substantial input, and all approved the final manuscript

\section{Consent for publication: N/A}

\section{Funding}

The study was funded by the UJMT Fogarty Global Health Fellowship program under NIH Fogarty international center grant \# D43TW009340 aimed at supporting research mentored training.

\section{Conflict of Interest}

The authors declare that the research was conducted in the absence of any commercial or financial relationships that could be construed as a potential conflict of interest.

\section{Acknowledgment}

The authors would like to thank Mr. Mawanda Denis (study coordinator) and the research assistants for collecting the data, the participants and community health workers for taking part, and finally the district authorities for permitting us to undertake the study.

\section{References}

1. UNAIDs JUNPoHA. Global AIDs update 2020. 20 Avenue Appia, 1211 Geneva 27, Switzerland; 2020. 
2. UNAIDS. Factsheet: global AIDS update. 2019. UNAIDS Geneva: 2019. Geneva; 2019.

3. International. UMoHal. 2011 Uganda AIDS Indicator Survey:. In: HEALTH MO, editor. Calverton, Maryland, USA: MOHand ICF International.2012. p. 13.

4. Pilcher CD, Tien HC, Eron JJ, Vernazza PL, Leu S-Y, Stewart PW, et al. Brief but Efficient: Acute HIV Infection and the Sexual Transmission of HIV. The Journal of Infectious Diseases. 2004;189(10):1785-92.

5. Kim J-H, Riolo RL, Koopman JS. HIV transmission by stage of infection and pattern of sexual partnerships. Epidemiology. 2010;21(5):676-84.

6. Chemaitelly H, Shelton JD, Hallett TB, Abu-Raddad L. Only a fraction of new HIV infections occur within identifiable stable discordant couples in sub-Saharan Africa. AIDS. 2013;27(2):251-60.

7. Kinuthia J, Singa B, McGrath CJ, Odeny B, Langat A, Katana A, et al. Prevalence and correlates of non-disclosure of maternal HIV status to male partners: a national survey in Kenya. BMC Public Health. 2018;18:671.

8. Dima AL, Stutterheim SE, Lyimo R, De Bruin M. Advancing methodology in the study of HIV status disclosure: The importance of considering disclosure target and intent. Social science \& medicine. 2014;108:166-74.

9. Frye V, Fortin P, MacKenzie S, Purcell D, Edwards LV, Mitchell SG, et al. Managing identity impacts associated with disclosure of HIV status: a qualitative investigation. AIDS care. 2009;21(8):1071-8.

10. Guthrie BL, de Bruyn G, Farquhar C. HIV-1-discordant couples in sub-Saharan Africa: explanations and implications for high rates of discordancy. Current HIV research. 2007;5(4):416-29.

11. Lingappa JR, Lambdin B, Bukusi EA, Ngure K, Kavuma L, Inambao M, et al. Regional differences in prevalence of HIV1 discordance in Africa and enrollment of HIV-1 discordant couples into an HIV-1 prevention trial. PLoS One. 2008;3(1):e1411.

12. Naigino R, Makumbi F, Mukose A, Buregyeya E, Arinaitwe J, Musinguzi J, et al. HIV status disclosure and associated outcomes among pregnant women enrolled in antiretroviral therapy in Uganda: a mixed methods study. Reproductive Health. 2017;14(1):107.

13. Ssali SN, Atuyambe L, Tumwine C, Segujja E, Nekesa N, Nannungi A, et al. Reasons for Disclosure of HIV Status by People Living with HIV/AIDS and in HIV Care in Uganda: An Exploratory Study. AIDS Patient Care and STDs. 2010;24(10):67581.

14. Kadowa I, Nuwaha F. Factors influencing disclosure of HIV positive status in Mityana district of Uganda. African health sciences. 2009;9(1):26-33.

15. Ruzagira E, Wandiembe S, Abaasa A, Bwanika AN, Bahemuka U, Amornkul P, et al. HIV incidence and risk factors for acquisition in HIV discordant couples in Masaka, Uganda: an HIV vaccine preparedness study. PLoS One. 2011;6(8):e24037.

16. Malamba SS, Mermin JH, Bunnell R, Mubangizi J, Kalule J, Marum E, et al. Couples at risk: HIV-1 concordance and discordance among sexual partners receiving voluntary counseling and testing in Uganda. JAIDS Journal of Acquired Immune Deficiency Syndromes. 2005;39(5):576-80.

17. Haberer JE, Kahane J, Kigozi I, Emenyonu N, Hunt P, Martin J, et al. Real-time adherence monitoring for HIV antiretroviral therapy. AIDS and Behavior. 2010;14(6):1340-6.

18. Obermeyer CM, Baijal P, Pegurri E. Facilitating HIV disclosure across diverse settings: a review. American journal of public health. 2011;101(6):1011-23.

19. Converse PJ, Mariam DH, Mulatu M, Mekonnen W, Kloos H. Bibliography on HIV/AIDS in Ethiopia and Ethiopians in the Diaspora: The 2012 Update. Ethiopian Journal of Health Development. 2013;27(2):156-86.

20. Smith R, Rossetto K, Peterson BL. A meta-analysis of disclosure of one's HIV-positive status, stigma and social support. AIDS care. 2008;20(10):1266-75.

21. Serovich JM, Mosack KE. Reasons for HIV disclosure or nondisclosure to casual sexual partners. AIDS education and prevention. 2003;15(1):70-80.

22. Atuyambe LM, Ssegujja E, Ssali S, Tumwine C, Nekesa N, Nannungi A, et al. HIV/AIDS status disclosure increases support, behavioural change and, HIV prevention in the long term: a case for an Urban Clinic, Kampala, Uganda. BMC Health Services Research. 2014;14(1):1-11.

23. Achilla T. Disclosure of HIV status to sexual partners amongst people who receive antiretroviral treatment in Kampala, Uganda. 2010.

24. Armitage $\mathrm{CJ}$, Conner M. Efficacy of the theory of planned behaviour: A meta-analytic review. British journal of social psychology. 2001;40(4):471-99.

25. King R, Katuntu D, Lifshay J, Packel L, Batamwita R, Nakayiwa S, et al. Processes and Outcomes of HIV Serostatus Disclosure to Sexual Partners among People Living with HIV in Uganda. AIDS and Behavior. 2008;12(2):232-43.

26. He H, Xu P, Xin Q, Zeng J, Zhang L, Sun D, et al. Study on spousal notification in HIV discordant couples and associated factors in four provinces of China. Zhonghua liu xing bing xue za zhi= Zhonghua liuxingbingxue zazhi. 2015;36(6):565-8. 
27. Kiula ES, Damian DJ, Msuya SE. Predictors of HIV serostatus disclosure to partners among HIV-positive pregnant women in Morogoro, Tanzania. BMC public health. 2013;13(1):1-9.

28. Kangwende RA, Chirenda J, Mudyiradima RF. HIV status disclosure among people living with HIV/AIDS at FASO, Mutare, Zimbabwe. 2009.

29. Marks G, Richardson JL, Maldonado N. Self-disclosure of HIV infection to sexual partners. American Journal of Public Health. 1991;81(10):1321-2.

30. Wyżgowski P, Rosiek A, Grzela T, Leksowski K. Occupational HIV risk for health care workers: risk factor and the risk of infection in the course of professional activities. Therapeutics and clinical risk management. 2016;12:989.

31. Anglewicz P, Chintsanya J. Disclosure of HIV status between spouses in rural Malawi. AIDS care. 2011;23(8):9981005.

32. Bradley-Springer L. Ending HIV in the United States by 2030. LWW; 2019.

33. Assefa Y, Gilks CF. Ending the epidemic of HIV/AIDS by 2030: Will there be an endgame to HIV, or an endemic HIV requiring an integrated health systems response in many countries? International Journal of Infectious Diseases. 2020;100:273-7.

34. Kahabuka C, Plotkin M, Christensen A, Brown C, Njozi M, Kisendi R, et al. Addressing the First 90: A Highly Effective Partner Notification Approach Reaches Previously Undiagnosed Sexual Partners in Tanzania. AIDS and Behavior. 2017;21(8):2551-60.

35. Cherutich P, Golden MR, Wamuti B, Richardson BA, Asbjornsdottir KH, Otieno FA, et al. Assisted partner services for HIV in Kenya: a cluster randomised controlled trial. The lancet HIV. 2017;4(2):e74-e82.

36. Kairania R, Gray RH, Kiwanuka N, Makumbi F, Sewankambo NK, Serwadda D, et al. Disclosure of HIV results among discordant couples in Rakai, Uganda: a facilitated couple counselling approach. AIDS care. 2010;22(9):1041-51.

37. World Health Organization W. Guidelines on HIV self-testing and partner notification: supplement to consolidated guidelines on HIV testing services: World Health Organization; 2016.

38. Rosenthal E, DeHeer D, Rush C, Holderby L. Focus on the future: a research agenda by and for the US community health worker field. Progress in Community Health Partnerships: Research, Education, and Action. 2008;2(3):225-35.

39. Mwai GW, Mburu G, Torpey K, Frost P, Ford N, Seeley J. Role and outcomes of community health workers in HIV care in sub-Saharan Africa: a systematic review. Journal of the International AIDS Society. 2013;16(1):18586.

40. Celletti F, Wright A, Palen J, Frehywot S, Markus A, Greenberg A, et al. Can the deployment of community health workers for the delivery of HIV services represent an effective and sustainable response to health workforce shortages? Results of a multicountry study. AIDS. 2010;24:S45-S57.

41. Kim MH, Ahmed S, Buck WC, Preidis GA, Hosseinipour MC, Bhalakia A, et al. The Tingathe programme: a pilot intervention using community health workers to create a continuum of care in the prevention of mother to child transmission of HIV (PMTCT) cascade of services in Malawi. Journal of the International AIDS Society. 2012;15:17389.

42. Zubair Lukyamuzi1, Ruth Nabisere Mirembe 3, Rita Nakalega1, Patience Atuhaire1, Hajira Kataike1, Bashir Ssuna 4,5, Mazen Baroudi 6 , Flavia Matovu Kiweewa1, Philippa Musoke 1, Lisa M Butler 7. . Community health workers improve HIV disclosure among HIV affected sexual partners in rural Uganda; a cluster non-randomized controlled trial. [Original Research]. Unpublished work.

43. Statistics UBo. The National Population and Housing Census 2014 - Main Report, Kampala, Uganda. 2016.

44. UBOS. UBOS Uganda demographic and health survey 2016: key indicators report. Kampala, Uganda (2017). 2017.

45. Garg S, Nanda P, Dewangan M. ROLE OF COMMUNITY HEALTH WORKERS IN IMPROVING TB DETECTION ON SCALE: A CASE STUDY FROM THE <em>MITANIN</em> PROGRAMME IN CHHATTISGARH, INDIA. BMJ Global Health. 2016;1(SuppI 1):A16-A7.

46. StataCorp L. Data analysis and statistical software. College Station, Texas: Author. 2008;8:9.

47. Exavery A, Charles J, Barankena A, Kuhlik E, Mubyazi GM, Kyaruzi C, et al. Accelerating caregivers' HIV status disclosure to community-based lay social welfare volunteers in Tanzania. AIDS Research and Therapy. 2021;18(1):9.

48. UNAIDs. UNAIDs. Peer education and VIH/SIDA: Concepts, uses and challenges. Geneva; 1999. 1999.

49. Han H-R, Kim K, Murphy J, Cudjoe J, Wilson P, Sharps P, et al. Community health worker interventions to promote psychosocial outcomes among people living with HIV-A systematic review. PLoS One. 2018;13(4):e0194928.

50. Ospina JE, Orcau À, Millet J-P, Sánchez F, Casals M, Caylà JA. Community health workers improve contact tracing among immigrants with tuberculosis in Barcelona. BMC public health. 2012;12(1):1-9.

51. Igumbor JO, Scheepers E, Ebrahim R, Jason A, Grimwood A. An evaluation of the impact of a community-based adherence support programme on ART outcomes in selected government HIV treatment sites in South Africa. AIDS care. 2011;23(2):231-6.

52. Ngonzi J, Mugyenyi G, Kivunike M, Mugisha J, Salongo W, Masembe S, et al. Frequency of HIV status disclosure, associated factors and outcomes among HIV positive pregnant women at Mbarara Regional Referral Hospital, southwestern Uganda. Pan Afr Med J. 2019;32:200-. 
53. Kipp W, Konde-Lule J, Saunders LD, Alibhai A, Houston S, Rubaale T, et al. Antiretroviral treatment for HIV in rural Uganda: two-year treatment outcomes of a prospective health centre/community-based and hospital-based cohort. PLoS One. 2012;7(7):e40902.

54. Chang LW, Kagaayi J, Nakigozi G, Ssempijja V, Packer AH, Serwadda D, et al. Effect of peer health workers on AIDS care in Rakai, Uganda: a cluster-randomized trial. PLoS One. 2010;5(6):e10923.

55. Jaffar S, Amuron B, Foster S, Birungi J, Levin J, Namara G, et al. Rates of virological failure in patients treated in a home-based versus a facility-based HIV-care model in Jinja, southeast Uganda: a cluster-randomised equivalence trial. The Lancet. 2009;374(9707):2080-9.

56. Ebuenyi ID, Ogoina D, Ikuabe PO, Harry TC, Inatimi O, Chukwueke OU. Prevalence Pattern and Determinants of disclosure of HIV status in an anti retroviral therapy Clinic in the Niger Delta Region of Nigeria. African journal of infectious diseases. 2014;8(2):22-6.

57. Skogmar S, Shakely D, Lans M, Danell J, Andersson R, Tshandu N, et al. Effect of antiretroviral treatment and counselling on disclosure of HIV-serostatus in Johannesburg, South Africa. AIDS care. 2006;18(7):725-30.

58. Hardon A, Gomez GB, Vernooij E, Desclaux A, Wanyenze RK, Ky-Zerbo O, et al. Do support groups members disclose less to their partners? The dynamics of HIV disclosure in four African countries. BMC Public Health. 2013;13(1):589.

59. Wohl AR, Galvan FH, Myers HF, Garland W, George S, Witt M, et al. Do social support, stress, disclosure and stigma influence retention in HIV care for Latino and African American men who have sex with men and women? AIDS and Behavior. 2011;15(6):1098-110.

60. Olley BO, Seedat S, Stein DJ. Self-disclosure of HIV serostatus in recently diagnosed patients with HIV in South Africa. African journal of reproductive health. 2004:71-6.

61. Erku TA, Megabiaw B, Wubshet M. Predictors of HIV status disclosure to sexual partners among people living with HIV/AIDS in Ethiopia. Pan Afr Med J. 2012;13:87.

62. Deribe K, Woldemichael K, Njau BJ, Yakob B, Biadgilign S, Amberbir A. Gender differences regarding barriers and motivators of HIV status disclosure among HIV-positive service users. SAHARA-J: Journal of Social Aspects of HIV/AIDS. 2010;7(1).

63. Mbichila TH, Chagomerana M, Tang JH, Haddad LB, Hosseinipour MC, Tweya H, et al. Partnership duration and HIV serodisclosure among people living with HIV/AIDS in Lilongwe, Malawi. International Journal of STD \& AIDS. 2018;29(10):987-93.

64. Antelman G, Fawzi MCS, Kaaya S, Mbwambo J, Msamanga GI, Hunter DJ, et al. Predictors of HIV-1 serostatus disclosure: a prospective study among HIV-infected pregnant women in Dar es Salaam, Tanzania. AIDS (London, England). 2001;15(14):1865.

65. Heyward WL, Batter VL, Malulu M, Mbuyi N, Mbu L, St Louis ME, et al. Impact of HIV counseling and testing among child-bearing women in Kinshasa, Zaïre. AIDS (London, England). 1993;7(12):1633-7.

66. Shacham E, Small E, Onen N, Stamm K, Overton ET. Serostatus Disclosure Among Adults with HIV in the Era of HIV Therapy. AIDS Patient Care and STDs. 2011;26(1):29-35.

67. Tesfaye T, Darega J, Belachew T, Abera A. HIV positive sero-status disclosure and its determinants among people living with HIV/AIDS following ART clinic in Jimma University Specialized Hospital, Southwest Ethiopia: a facility-based crosssectional study. Archives of Public Health. 2018;76(1):1-10.

68. Reis RK, Sousa LRM, Melo ES, Fernandes NM, Sorensen W, Gir E. Predictors of HIV Status Disclosure to Sexual Partners Among People Living with HIV in Brazil. AIDS and Behavior. 2021;25(11):3538-46.

69. Akani C, Erhabor O. Rate, pattern and barriers of HIV serostatus disclosure in a resource-limited setting in the Niger delta of Nigeria. Tropical doctor. 2006;36(2):87-9.

70. Makin JD, Forsyth BWC, Visser MJ, Sikkema KJ, Neufeld S, Jeffery B. Factors Affecting Disclosure in South African HIV-Positive Pregnant Women. AIDS Patient Care and STDs. 2008;22(11):907-16.

71. Maman S, van Rooyen H, Groves AK. HIV status disclosure to families for social support in South Africa (NIMH Project Accept/HPTN 043). AIDS Care. 2014;26(2):226-32.

72. Abdool Karim Q, Dellar RC, Bearnot B, Werner L, Frohlich JA, Kharsany ABM, et al. HIV-Positive Status Disclosure in Patients in Care in Rural South Africa: Implications for Scaling Up Treatment and Prevention Interventions. AIDS and Behavior. 2015;19(2):322-9. 